\title{
Numerical and Wind Tunnel Simulation Studies of the Flow Field and Pollutant Diffusion around a Building under Neutral and Stable Atmospheric Stratifications
}

\author{
Dong-Peng Guo And Peng Zhao \\ Department of Environment Science and Engineering, Taiyuan University of Science and Technology, Taiyuan, China \\ Ren-Tai Yao, Yun-Peng Li, And Ji-Min Hu \\ China Institute for Radiation Protection, Taiyuan, China \\ DAN FAN \\ National Nuclear Emergency Response Technical Assistance Center, Beijing, China
}

(Manuscript received 20 February 2019, in final form 25 August 2019)

\begin{abstract}
In this paper, the $k-\varepsilon$ renormalization group (RNG) turbulence model is used to simulate the flow and dispersion of pollutants emitted from a source at the top of a cubic building under neutral and stable atmospheric stratifications, the results of which were compared with corresponding wind tunnel experiment results. When atmosphere stratification is stable, the separation zones on the sides and at the top of a building are relatively smaller than those under neutral conditions, and the effect of the building in the horizontal direction is stronger than that in the vertical direction. The variation in turbulent kinetic energy under stable conditions is significantly lower than that under neutral conditions. The effect of atmospheric stratification on the turbulent kinetic energy becomes gradually more prominent with increased distance. When atmosphere conditions are stable, the vertical distribution of the plume is smaller than that of neutral conditions, but the lateral spread and near-ground concentration are slightly larger than those of neutral conditions, mainly because stable atmospheric stratification suppresses the vertical motions of airflow and increases the horizontal spread of the plume.
\end{abstract}

\section{Introduction}

As pollutants from low stacks near a building flow into the atmospheric environment, complex local disturbances are encountered and the dispersion trajectory of pollutants is changed due to the effect of the building and atmospheric stability, thus making the transport and diffusion processes of pollutants around buildings more complicated. Furthermore, the effect of atmospheric stability on the diffusion of radioactive materials is significant. At present, most wind tunnel experiments used to study the dispersion of atmospheric pollutants are based on neutral conditions; however, the actual atmosphere is completely different. Atmospheric stratification near the surface layer often transitions among stable, unstable, and neutral conditions. Hence, to simulate the dispersion of atmospheric pollutants in a

Corresponding author: Guo Dong-Peng, guodp@126.com more accurate manner and investigate the impact of these pollutants on the environment, it is necessary to study pollutant dispersion under different atmospheric stratifications.

An atmospheric boundary layer wind tunnel can be used to model complex atmospheric flow and dispersion over a complex terrain. Meroney and Cermak (1967) studied the atmospheric flow surrounding San Nicolas Island under neutral and stable conditions in the wind tunnel at Colorado University. The results showed qualitative similarity in the structure of the thermal field between the prototype and the model under thermal inversion conditions. Uehara et al. (2000) studied the effects of atmospheric stability on the flow field and dispersion in street canyons via wind tunnel experiments. The following results were observed: 1 ) when atmospheric stratification is stable, the vortex in the cavity region of buildings tends to weaken but is enhanced under other conditions; 2) the pollutant concentrations 
in the street canyon are higher under stable conditions; and 3) a portion of the contaminants returns from the higher part to the lower part of the canyon, and the amount of returned contaminants is determined by the atmospheric stability. Yassin et al. (2005) studied the dispersion of pollutants in street canyons under different thermal stratifications using wind tunnels and field experiments. Yassin (2013) studied the effect of an isolated cubical building on near-field dispersion under different atmospheric stratifications. Mavroidis et al. (1999) studied the effect of thermal stability on the nearfield dispersion around an isolated cube through field experiments. Mavroidis et al. (2003) performed field and wind tunnel experiments to investigate the influences of isolated buildings of different shapes on pollutant dispersion. The results showed that the lateral distribution of the plume in the field experiment was larger than that of the wind tunnel experiment; however, the central-axis concentrations of the field experiment were slightly smaller than those in the wind tunnel. This result is attributable to the effect of additional wind meander occurring in the atmosphere. Yao et al. (2002) studied the flow field and diffusion of pollutants around building complexes under neutral conditions through wind tunnel experiments. The results showed that the effect of buildings on pollutant dispersion was very complicated, where the dispersion was not only inhomogeneous but also varied with the angle between the approaching flow and the windward side as well as the configuration of the building. Furthermore, dispersion was not completely homogeneous on the leeward side of the building.

With the development of computational fluid dynamics (CFD), simulation has been used to predict the characteristics of flow and the dispersion of atmospheric pollutants around various buildings. Tominaga and Stathopoulos $(2009,2013)$ and Santiago et al. (2017) simulated the flow field and concentration field around a complicated building in three-dimensional space using the CFD technique. Meroney et al. (1999) and Tominaga et al. (2004) studied the influence of a standard cubic building on the dispersion of pollution from a fixed emission source by CFD simulations and compared the results with data from previous wind tunnel experiments. Endalew et al. (2009) studied the dispersion of pollutants in the atmospheric boundary layer by CFD simulations and validated the findings through wind tunnel experiments. Tominaga et al. (2008) and Mavroidis et al. (2012) studied the influences of buildings of different shapes on the flow field in the atmospheric boundary layer using various turbulence models. They found that the CFD simulation could evaluate the influences of buildings on the flow field, which were in agreement with the results of wind tunnel experiments. Santos et al. (2009) studied the effect of a single building on pollutant dispersion under different thermal stabilities via CFD simulation and compared the results with data from wind tunnel experiments. Pieterse and Harms (2013) studied the influence of a hill on flow fields under different atmospheric stratifications. They found that the attachment point was forward under unstable conditions, whereas the attachment point was backward under stable conditions. Ai and Mak (2017) and Flores et al. (2013) used CFD simulation to study the effects of complex blocks on the flow field. Blocken et al. (2007) studied the effects of the surface roughness and a complex building on the flow field via CFD simulation. Ashrafi et al. (2017) and Orkomi et al. (2018) used the CFD technique to study plume rise and dispersion under different thermal stratifications.

At present, there are still certain weaknesses in CFD simulations. Therefore, it is necessary to verify the adaptability of the CFD simulation method on the dispersion of atmospheric pollutants by using corresponding wind tunnel test results (Jiang et al. 2003). This paper studied pollutant dispersion under different atmospheric stabilities via wind tunnel experiments and CFD simulations and proposed an establishment method for a numerical thermally stratified boundary layer wind tunnel. Additionally, the effect of atmospheric stability on pollutant dispersion and the flow field was further validated.

\section{Wind tunnel experiments}

The current experiments were performed in the Atmospheric Boundary Layer Wind Tunnel Laboratory of the China Institute for Radiation Protection. The wind tunnel was a direct-flow air-blowing wind tunnel; its length was $36 \mathrm{~m}$, and the length of the test section was $17 \mathrm{~m}$, with a width of $1.5 \mathrm{~m}$ and a height of $1 \mathrm{~m}$. The ambient temperature was controlled in the range from $10^{\circ}$ to $85^{\circ} \mathrm{C}$ by adjusting the distribution of flow at the inlet of the test section and installing heating and cooling panels. Some spires were set at the entrance of the wind tunnel. The vertical profile of the wind velocity was achieved by adjusting the windward angle of the spire while large-scale turbulence was generated. Roughness elements of two different sizes $(50 \mathrm{~mm} \times 80 \mathrm{~mm} \times$ $100 \mathrm{~mm}$ and $20 \mathrm{~mm} \times 30 \mathrm{~mm} \times 30 \mathrm{~mm}$ ) were placed downstream of the spires. Large and small elements were lined up in four rows. The intervals between the two kinds of elements were 150 and $300 \mathrm{~mm}$ to ensure that the turbulence intensity in the wind tunnel coincides with that in the real atmosphere. 
TABLE 1. The main parameters of different atmospheric stratifications. Environmental temperature is uniform in the vertical direction and the Richardson number $\mathrm{Ri}$ is zero under neutral conditions. Environmental temperature increases with elevation and $\mathrm{Ri}$ is larger than zero under stable conditions.

\begin{tabular}{cccccccc}
\hline \hline Atmospheric stability & $u_{\mathrm{ref}}\left(\mathrm{m} \mathrm{s}^{-1}\right)$ & $u_{*}\left(\mathrm{~m} \mathrm{~s}^{-1}\right)$ & $y_{0}(\mathrm{~m})$ & $T_{1}\left({ }^{\circ} \mathrm{C}\right)$ & $T_{2}\left({ }^{\circ} \mathrm{C}\right)$ & $\mathrm{Re}$ & $\mathrm{Ri}$ \\
\hline Neutral & 1.3 & 0.4 & 0.006 & 28 & 28 & $2 \times 10^{5}$ & 0.0 \\
Stable & 1.3 & 0.04 & 0.002 & 12 & 45 & $2 \times 10^{5}$ & 0.016 \\
\hline
\end{tabular}

A stable atmospheric boundary layer was modeled using typical temperature profiles. The vertical temperature gradient was set by adjusting the inflow temperature control system, temperature profile cart and bottom cooling panels. In the experiments, the wind velocity and temperature were simultaneously measured by coupled cold- and hot-wire probes. The hotwire probes were composed of a cold wire and an $\mathrm{X}$-array hot wire. The cold-wire probe was used for temperature measurements. The X-array hot wire was used for velocity measurements. The hot-wire anemometers were calibrated by an automatic calibration unit that was able to calibrate the wind velocities and angles of the probes.

The model scale was 1:250, the employed model was a standard cubic building, and its length $L$, width $D$, and height $H$ were $150 \mathrm{~mm}$. In the test process, the incoming flow satisfied the following conditions. 1) The vertical profile of mean streamwise velocity was subject to the power law (with an index of $P=$ 0.12 ); the streamwise velocity $u$ is $1.3 \mathrm{~m} \mathrm{~s}^{-1}$ at a height of $500 \mathrm{~m} .2$ ) The changes in atmospheric condition were achieved by controlling the bulk Richardson number $\mathrm{Rb}\left[=g \delta \Delta T /\left(T_{1} u^{2}\right)\right.$, where $g$ is the acceleration due to gravity $\left(=9.8 \mathrm{~m} \mathrm{~s}^{-2}\right), \delta$ is the depth of the boundary layer $(=300 \mathrm{~mm}), \Delta T$ is the temperature difference, $T_{1}$ is the temperature of the ground, and $u$ is the wind velocity; the appendix lists and defines the symbols used in this paper]. 3) The kinematic, dynamic, and boundary condition similarities were satisfied. The kinematic similarity was determined by the equivalence of the upstream wind shear exponent and the turbulent intensity profiles in the surface boundary layer. The dynamic similarity was determined by the similarity criteria of the Reynolds number Re, which meant that the Reynolds number of the typical turbulence of the airflow in the model area was high enough $(\operatorname{Re}>11000)$. The latter ensured the dynamic similarity of the airflow between the experimental model and the prototype under certain experimental wind velocities. Berkowicz and Prahm (1982) proposed the profiles of wind velocity and temperature for different atmospheric stratifications based on the relation between the Monin-Obukhov length and surface heat fluxes. In this paper, to distinctly reflect the effect of thermal stratification on the pollutant dispersion, the same wind shear exponent and reference velocity are used in the neutral and stable simulated boundary layers. The depth of boundary layer is approximately equal to the height at which the velocity is approximately $99 \%$ of the maximum wind speed. The maximum measurement height is approximately $0.46 \mathrm{~m}$ in the test section. The maximum velocity was observed at a height of $0.3 \mathrm{~m}$. Therefore, the depth of the boundary layer was considered to be approximately $0.3 \mathrm{~m}$. The main parameters of the stable and neutral conditions are shown in Table 1.

The experiments considered the influence of the recirculation produced by a standard cubic building on the dispersion of pollutants from exits on the building under different atmospheric stabilities. The height of the stack was $165 \mathrm{~mm}(1.1 \mathrm{H})$, the inner diameter was $4 \mathrm{~mm}$, and the outer diameter was $6 \mathrm{~mm}$. Carbon monoxide was used as a tracer gas, and the concentrations at the different sites were calculated by the normalized concentration $K=C^{*} U_{0} H^{2} / Q$, where $C^{*}$ is the volume concentration at different downwind distances, $U_{0}$ is the mean streamwise velocity at the top of the simulated boundary layer, $H$ is the height of the building, and $Q$ is the source volume flow rate (the emitted velocity is $50 \%$ of the mean streamwise velocity at the building height).

Sampling in the vertical direction was conducted at four different downwind locations $(x / H=0.75,1.0$, 1.5, and 2.0). The vertical sampling intervals are $0.05 H(0.75 \mathrm{~cm})$ for $z<20 \mathrm{~cm}$ and $0.1 H(1.5 \mathrm{~cm})$ for $z>20 \mathrm{~cm}$. The sampling system is a synchronized automatic tracer measurement system that includes a shunt sampling unit, a centralized measurement unit, and an industrial personal computer unit. The infrared gas analyzer was used as a measurement instrument. The sampling unit of this system was more precise than that of the previous single-point sampling method. The primary parameters included the following: 1) gas components and concentration range: carbon monoxide over 0-2000 ppm, 10\% (transform automatically); 2) alarm range: $10 \%-90 \%$ full scale; 3 ) the response time of synchronized measurement is less than $20 \mathrm{~min}$; and 4) the variation range of instrument sensitivity was $\pm 1 \%$ full scale, and its response time was shorter 


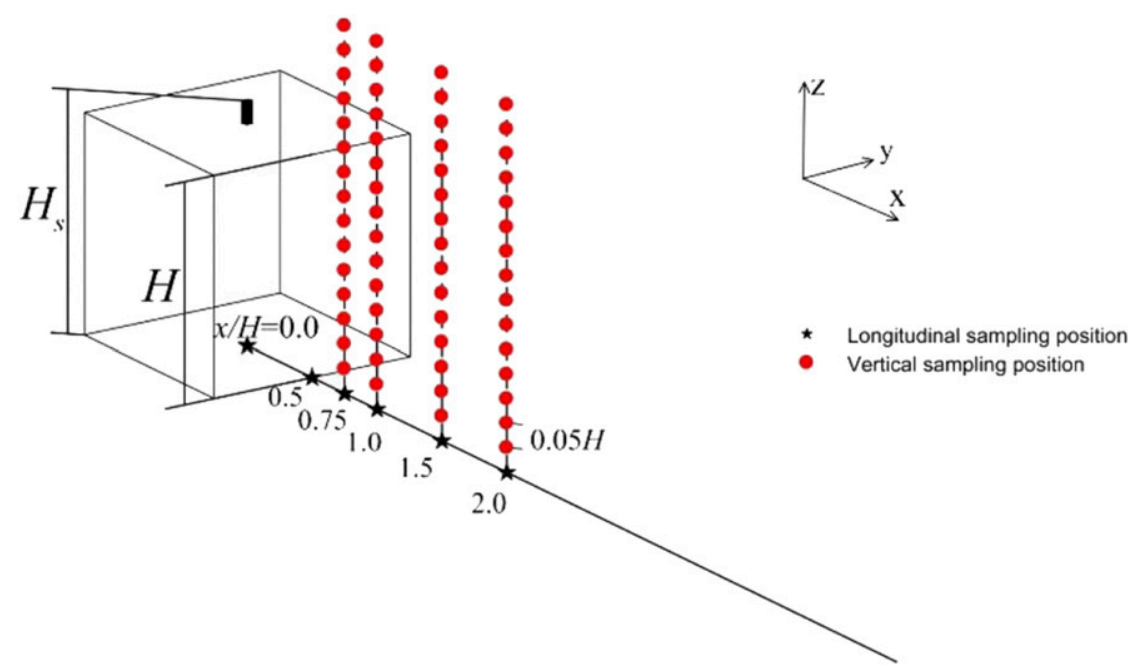

FIG. 1. A schematic of the building with a pollution source.

than 30 s. Figure 1 shows a schematic of the building with the pollution source.

\section{Numerical simulation}

The CD-adapco, Ltd. (now part of Siemans), "STARCD 3.26" software package was used as the computing platform. To compare the results of the wind tunnel experiments, the size of the computational domain was $17 \mathrm{~m} \times 1.5 \mathrm{~m} \times 1.0 \mathrm{~m}$ (length, width, and height, respectively) and the standard cubic model was the same as that in the wind tunnel. The height of the cube is $150 \mathrm{~mm}$, and the total height of the model is $165 \mathrm{~mm}$ $(1.1 H)$. Figure 2 shows the position of the building model within the computational domain.

A hexahedral grid was used because it has a suitable topological structure. A finer grid was used for regions of the ground and building surfaces. The minimum grid size was $5 \mathrm{~mm}$ on the building surface, and the maximum grid size was $30 \mathrm{~mm}$ within the domain. The total number of cells was approximately 2 million in the computational domain. A gridindependence analysis was performed by using two different meshes. The minimum sizes of the fine and coarse meshes were 2 and $10 \mathrm{~mm}$, respectively. Figure 3 shows that the discrepancies resulting from the different meshes are small.

The inlet boundary conditions and the vertical distributions of the mean streamwise velocity $u$, temperature and turbulent kinetic energy $k$ were provided by using the experimental data as interpolated values of the approximation curves (Fig. 4). The emission conditions of the pollution source were the same as those of the wind tunnel experiments.

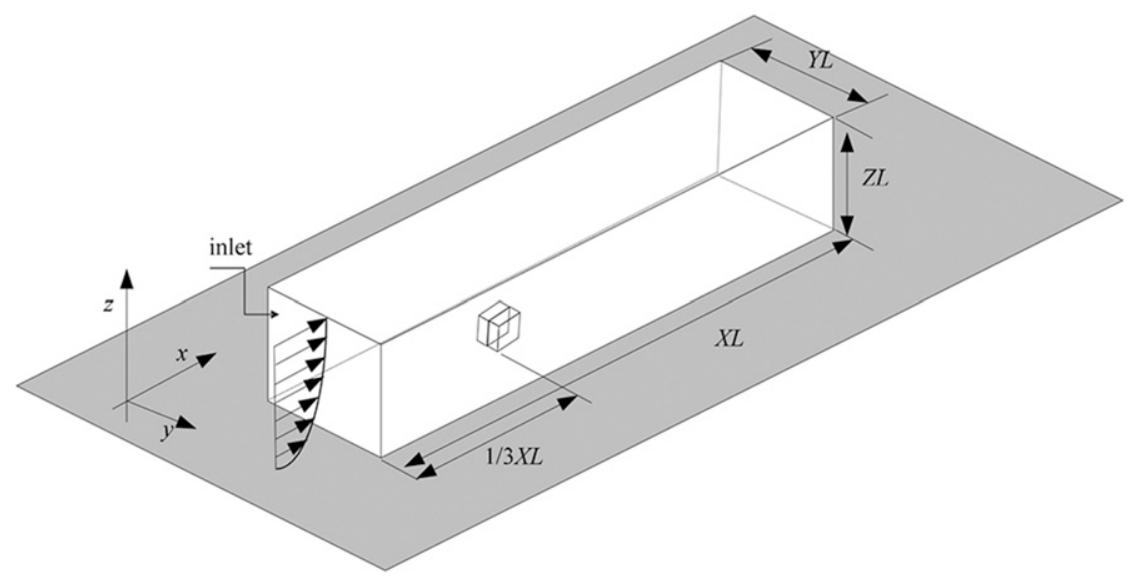

FIG. 2. The position of the building in the computational domain. 


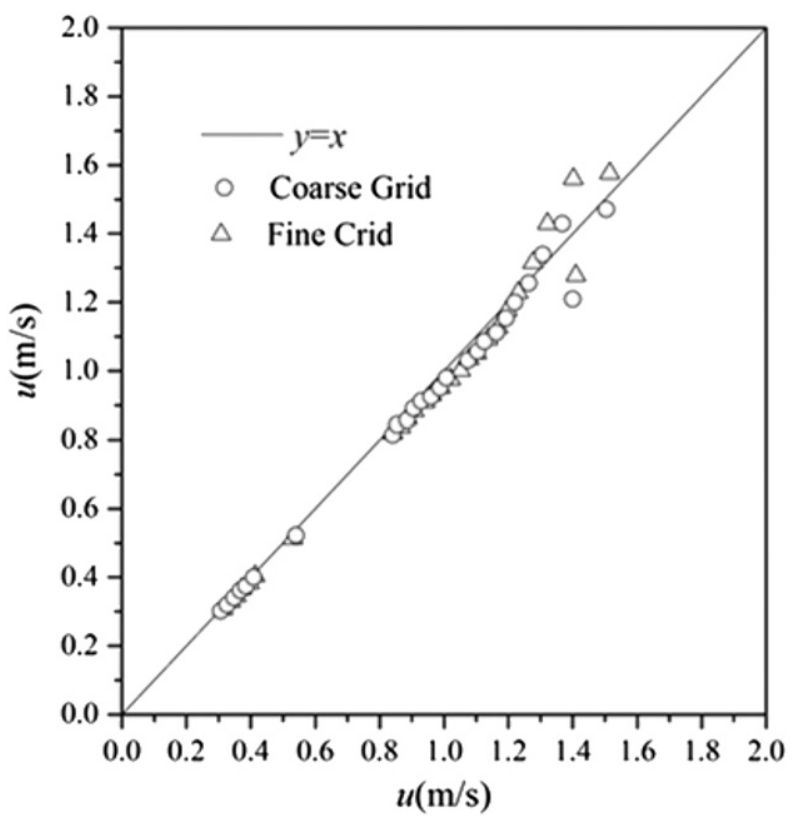

FIG. 3. A grid-independence analysis.

The different thermal stratifications were simulated by adjusting the temperature of the top and the bottom in the domain. At the outlet boundary, the derivatives of all properties were zero. The friction velocity $u_{*}$, temperature $T_{1}$, and roughness $y_{0}$ were set on the ground. The boundary conditions at the top and sides were smooth, and the temperature $T_{2}$ was defined at the top. A no-slip condition was imposed on the walls of the building. The roughness of the building surface was $0.001 \mathrm{~m}$. The main parameters under different thermal stratifications are shown in Table 1.

The flow around the sharp building had complicated characteristics of separation, backflow, etc. The standard $k-\varepsilon$ turbulence model could not simulate the complicated characteristics of flow around the sharp body; however, the $k-\varepsilon$ renormalization group (RNG) turbulence model better simulated the recirculation around the sharp body (Tominaga et al. 2008). In this study, the closure Navier-Stokes equation was solved according to the $k-\varepsilon$ (RNG) model. The basic equations of the model consisted of the continuity and momentum equations. These equations were not solved directly; instead, two equations were introduced with regard to the turbulent kinetic energy $k$ and the dissipation rate $\varepsilon$, which relied on the isotropic turbulent viscosity to calculate the turbulent stress. Standard wall functions were used for the walls, the semi-implicit method for pressure linked equations-consistent (SIMPLEC) algorithm was used to solve the governing equations, and the discretization scheme of the advection term was the quadratic upstream interpolation for convective kinematics (QUICK). The residual variable should be smaller than $10^{-4}$. The turbulence model constants are shown in Table 2.

The $k-\varepsilon$ (RNG) turbulence model equations are as follows:
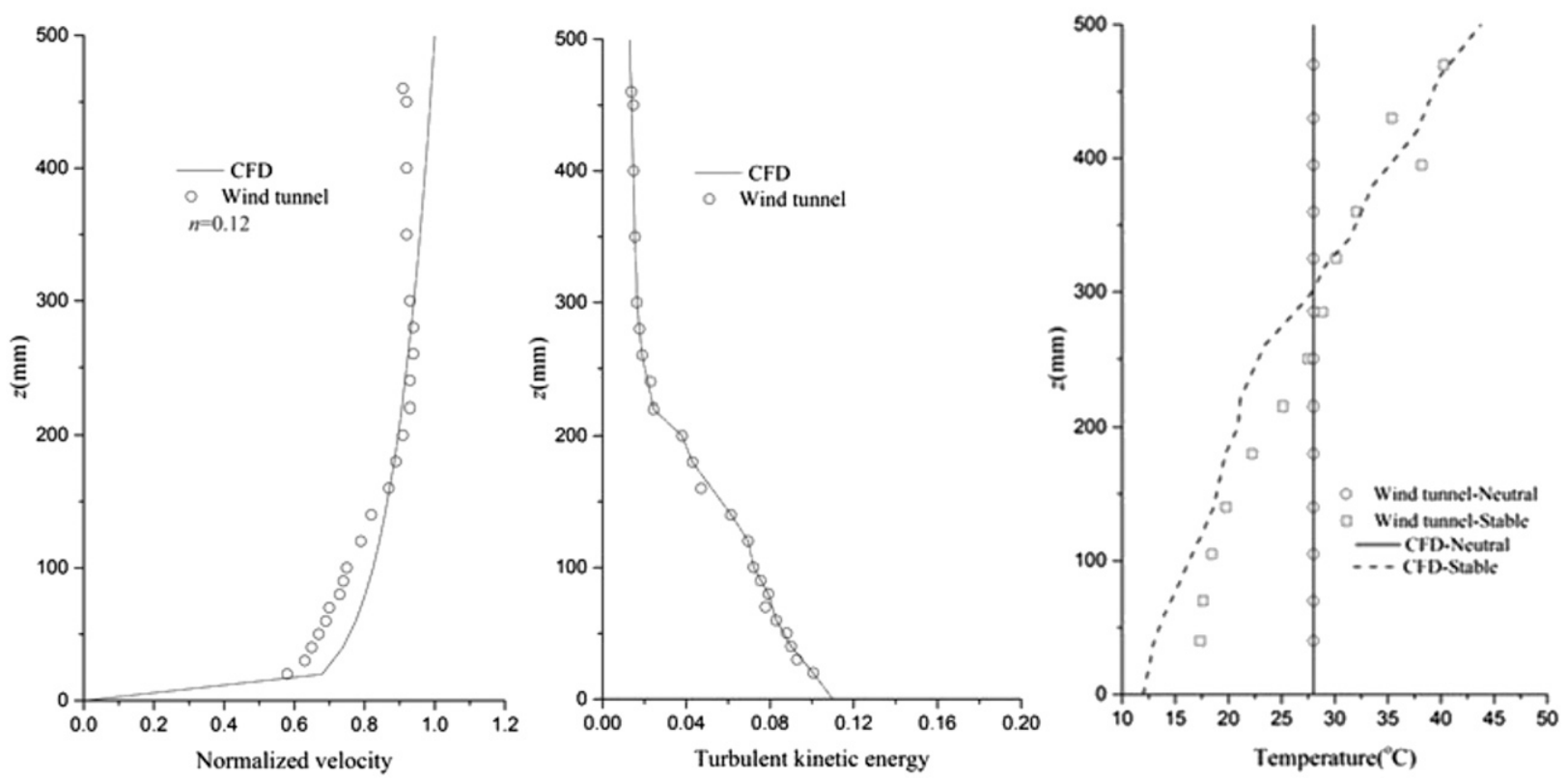

FIG. 4. Vertical distributions of the mean velocity, turbulence kinetic energy, and temperature in the simulated boundary layer. 
TABLE 2. The $k-\varepsilon$ (RNG) turbulence model constants.

\begin{tabular}{cccccccccc}
\hline \hline$C_{\mu}$ & $C_{\varepsilon 1}$ & $C_{\varepsilon 2}$ & $C_{\varepsilon 3}$ & $C_{\varepsilon 4}$ & $\sigma_{k}$ & $\sigma_{\varepsilon}$ & $\sigma_{h}$ & $\eta_{0}$ & $\beta$ \\
\hline 0.085 & 1.42 & 1.68 & 1.42 & -0.387 & 0.719 & 0.719 & 0.9 & 4.38 & 0.012 \\
\hline
\end{tabular}

$$
\begin{aligned}
& \frac{\partial}{\partial t}(\rho k)+\frac{\partial}{\partial x_{j}}\left[\rho k u_{j}-\left(\mu+\frac{\mu_{t}}{\sigma_{k}}\right) \frac{\partial k}{\partial x_{j}}\right] \\
& =\mu_{t}\left(P_{T}+P_{B}\right)-\rho \varepsilon-\frac{2}{3}\left(\mu_{t} \frac{\partial \mu_{i}}{\partial x_{i}}+\rho k\right) \frac{\partial u_{i}}{\partial x_{i}}, \\
& \frac{\partial}{\partial t}(\rho \varepsilon)+\frac{\partial}{\partial x_{j}}\left[\rho \varepsilon u_{j}-\left(\mu+\frac{\mu_{t}}{\sigma_{\varepsilon}}\right) \frac{\partial \varepsilon}{\partial x_{j}}\right] \\
& =C_{\varepsilon 1} \frac{\varepsilon}{k}\left[\mu_{t} P_{T}-\frac{2}{3}\left(\mu_{t} \frac{\partial \mu_{i}}{\partial x_{i}}+\rho k\right) \frac{\partial \mu_{i}}{\partial x_{i}}\right]+C_{\varepsilon 3} \frac{\varepsilon}{k} \mu_{t} P_{B} \\
& -C_{\varepsilon 2} \rho \frac{\varepsilon^{2}}{k}+C_{\varepsilon 4} \rho \varepsilon \frac{\partial u_{i}}{\partial x_{i}}-\frac{C_{\mu} \eta^{3}\left(1-\eta / \eta_{0}\right)}{1+\beta \eta^{3}} \frac{\rho \varepsilon^{2}}{k}, \\
& P_{T}=S_{i j} \frac{\partial u_{i}}{\partial x_{j}} \\
& P_{B}=-\frac{g_{i}}{\sigma_{h}} \frac{1}{\rho} \frac{\partial \rho}{\partial x_{i}} \\
& \eta=S \frac{k}{\varepsilon} \\
& S_{i j}=\frac{\partial u_{i}}{\partial x_{j}}+\frac{\partial u_{j}}{\partial x_{i}}, \quad \text { and } \\
& S=\frac{k}{\varepsilon}\left(\frac{1}{2} S_{i j} S_{i j}\right)^{1 / 2} \text {. }
\end{aligned}
$$

\section{Results and discussion}

This paper focused on examining the effects of the stable and neutral atmospheric stratifications on the flow and dispersion in the near wake of a building when the stack was on top of the standard cubic building. The study of the characteristics of the flow and the concentration distribution was conducted at four different locations along the central axis $(y=0), x / H=0.75,1.0$, 1.5, and 2.0 (Fig. 1).

\section{a. Impact of the building on flow}

The numerical simulations evaluated the influence of the building on its near flow field using the $k-\varepsilon$ (RNG) turbulence model. The velocity was normalized to eliminate the influence of the different wind velocities. The nondimensional velocity $\left(u / U_{0}\right)$ was the ratio of the local longitudinal mean velocity $u$ to the mean velocity $U_{0}$ at the top of the simulated boundary layer. The horizontal and vertical profiles of the flow field under neutral and stable conditions in the numerical simulation are shown in Figs. 5 and 6, respectively. Figure 7 compares the vertical profiles of longitudinal velocities with the approaching flow at different downwind positions.

Figures 5 and 6 show the details of flow in the wake and recirculation regions under neutral and stable conditions in the numerical simulation. The variation in the flow field on the windward side of the building was distinct. The wind velocities on the central plane have converted into horizontal and vertical momentum. Recirculation appears on the leeward side of the building, and a double vortex recirculation has formed (horseshoe vortices). The direction of the local velocity vectors became vertically downward. The influences of the cubic building on the flow field basically remained consistent under neutral and stable conditions. The stationary point on the windward side of the building is observed at $z / H=2 / 3$ under neutral conditions and at $z / H=1 / 2$ under stable conditions. The cavity zones are approximately at $z / H=$ 1.0 under neutral conditions and at $z / H=1.2$ under stable conditions. The attachment point on the leeward side of the building is approximately at $x / H=2.0$ for neutral conditions and at $x / H=3.0$ for stable conditions. However, the attachment point on the top of the building was not reproduced by the numerical simulation under neutral and stable conditions. Tominaga and Stathopoulos (2009) validated that the attachment points on the top and leeward side of the building were approximately at $z / H=0.08-0.4$ and at $x / H=2.0-3.0$, respectively, by using different modified $k-\varepsilon$ models. Zhang et al. (1996) studied the effect of a building on flow field and diffusion under different thermal stratifications via numerical simulations and tank experiments. They found that the length of the recirculation region on the leeward side of a building was longer under stable conditions because stable stratification enhanced the downward motion of the flow field, which is in agreement with the results obtained in the present study.

According to the characteristics of the whole flow field, the separated flow regions near the two sides and top of the building under stable conditions are relatively smaller than those under neutral conditions. The influence of the building on the horizontal direction is more pronounced than that on the vertical direction, mainly because the vertical velocity components on the windward plane are restrained by the momentum equation. Thus, the numerical simulation can reproduce the influences resulting from the building, including the displacement zone, wake region, cavity 


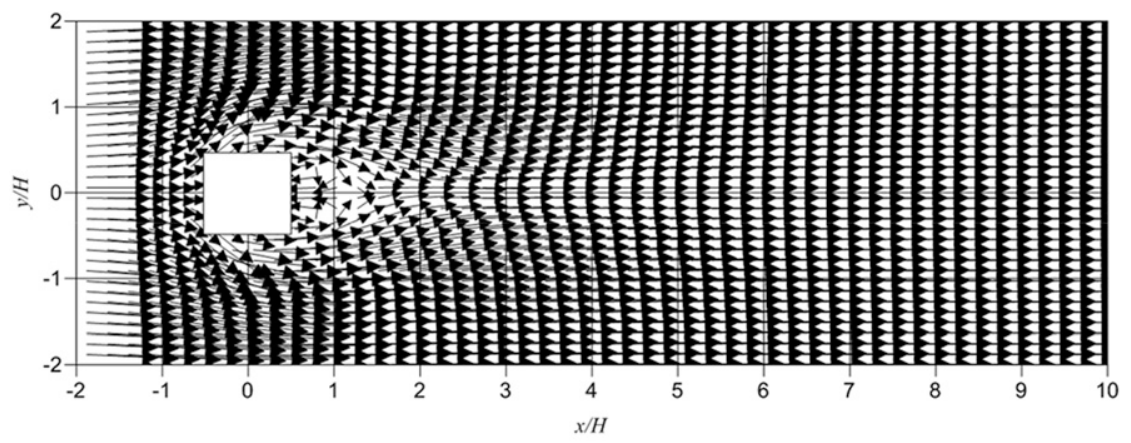

(a) neutral stratified condition

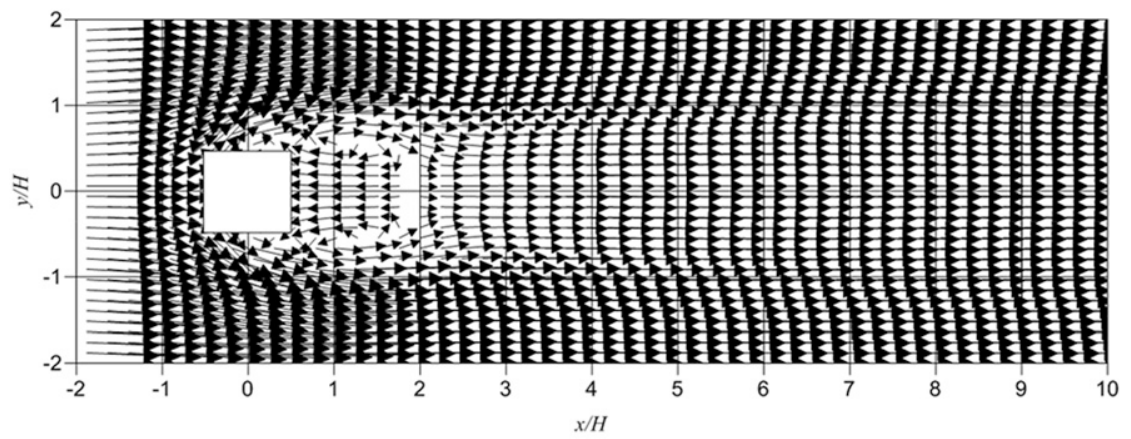

(b) stable stratified condition

FIG. 5. Horizontal profiles of flow field structure $(z / H=0.05)$.

zone, near-ground stagnation, and inverse flow on the top of the building. Additionally, the inverse flow near the two sides of the building and the horseshoe vortex in the cavity zone downwind of the building are well represented.

As shown in Fig. 7, the wind velocity in the near wake of the building (including the recirculation zone) decreases significantly in the downwind direction. When the atmospheric stratification is stable, the deficit in velocity is slightly larger than that under neutral conditions. The maximum deficit is approximately $30 \%$ of the corresponding approaching flow. Airflow mixing gradually becomes homogeneous, and the wind velocity is gradually restored to the state of

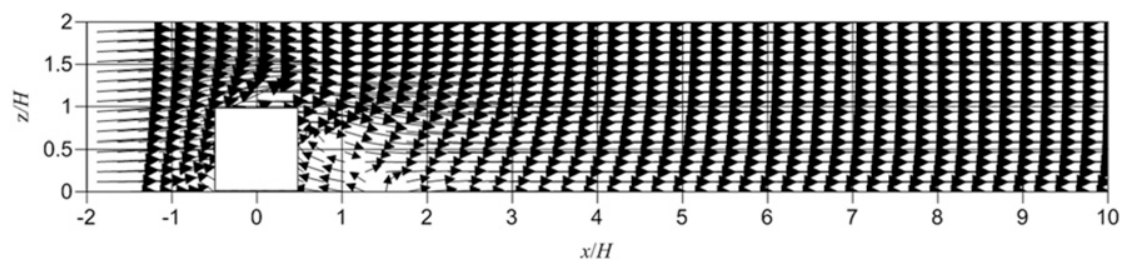

(a)neutral stratified condition

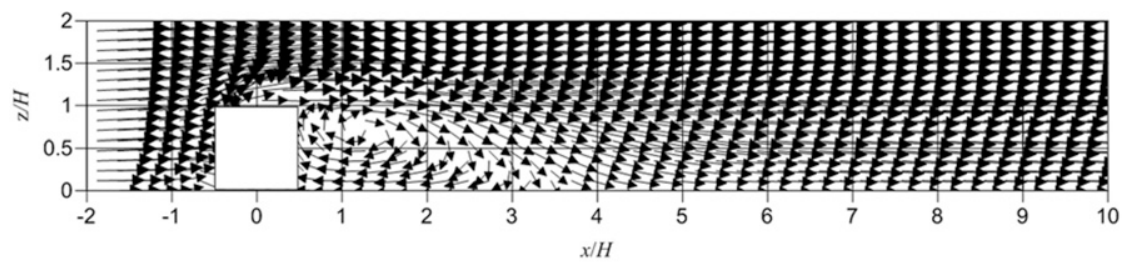

(b) stable stratified condition

FIG. 6. Vertical profiles of flow field structure. 


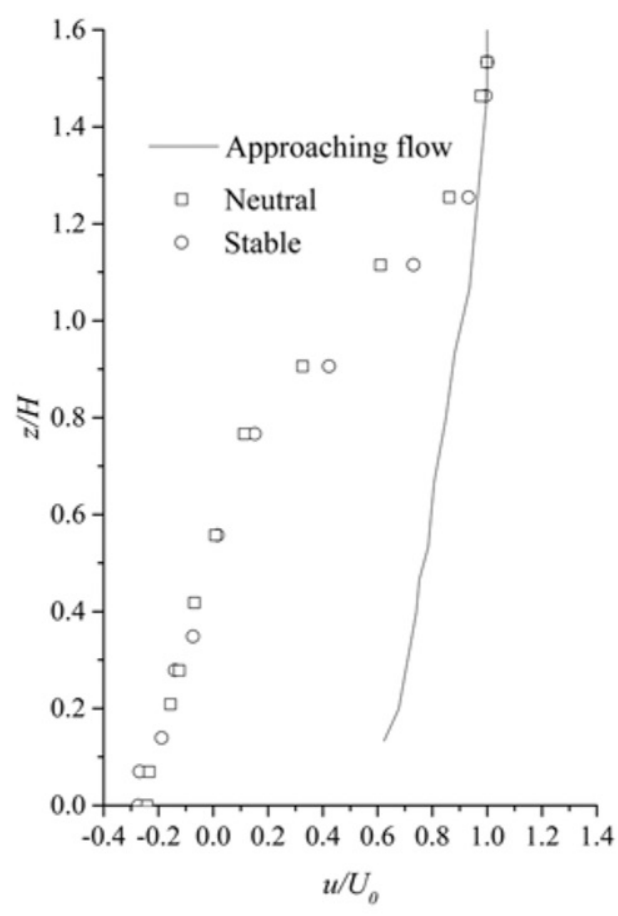

$x / H=0.75$

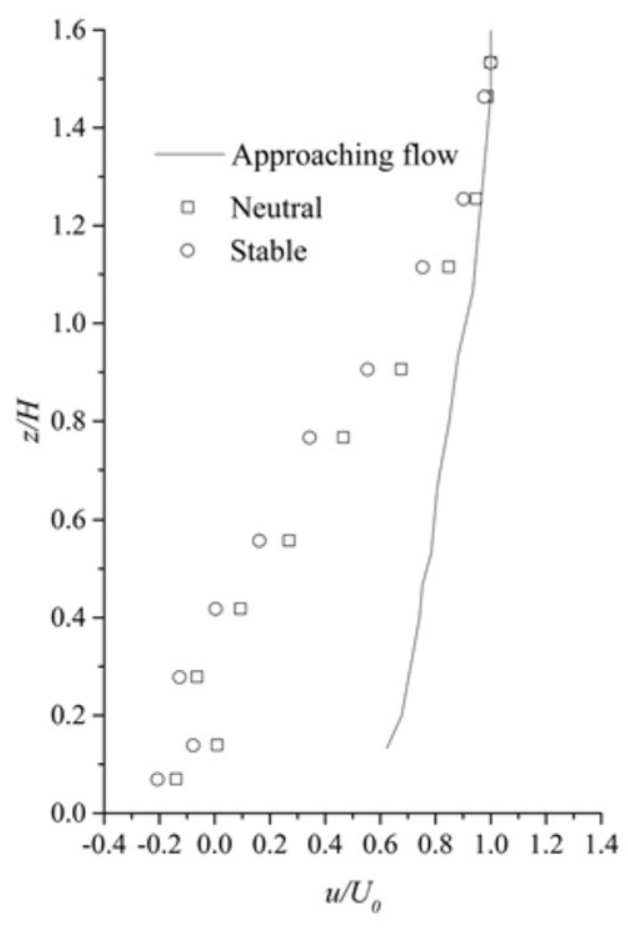

$$
x / H=1.5
$$

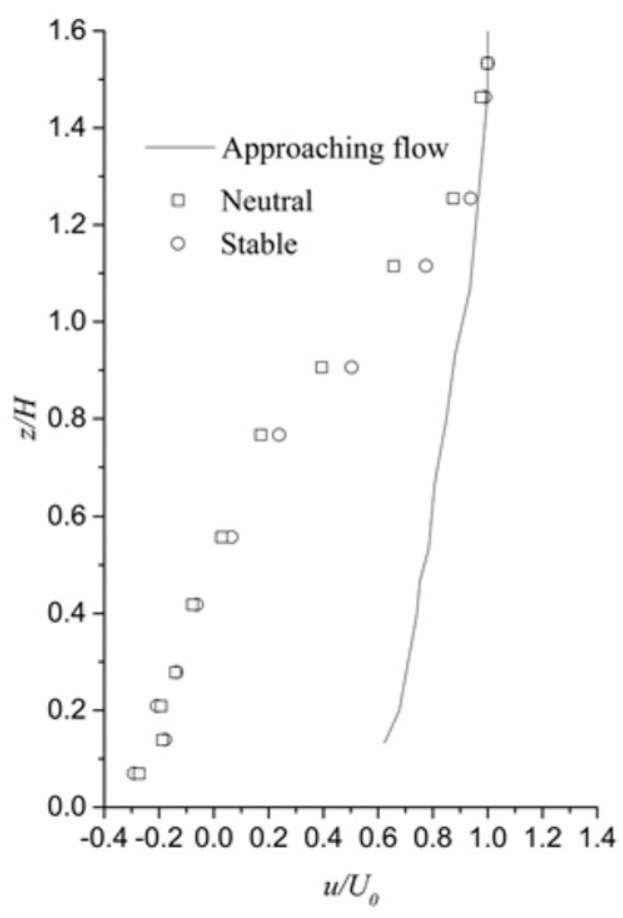

$x / H=1.0$

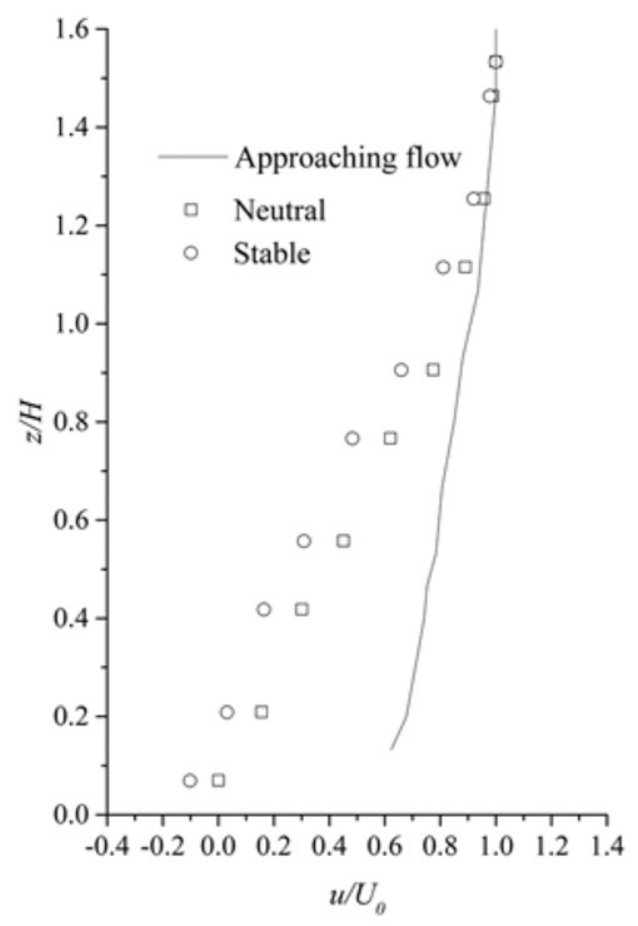

$x / H=2.0$

FIG. 7. Vertical profiles of mean velocity component in the longitudinal direction $u / U_{0}$. 


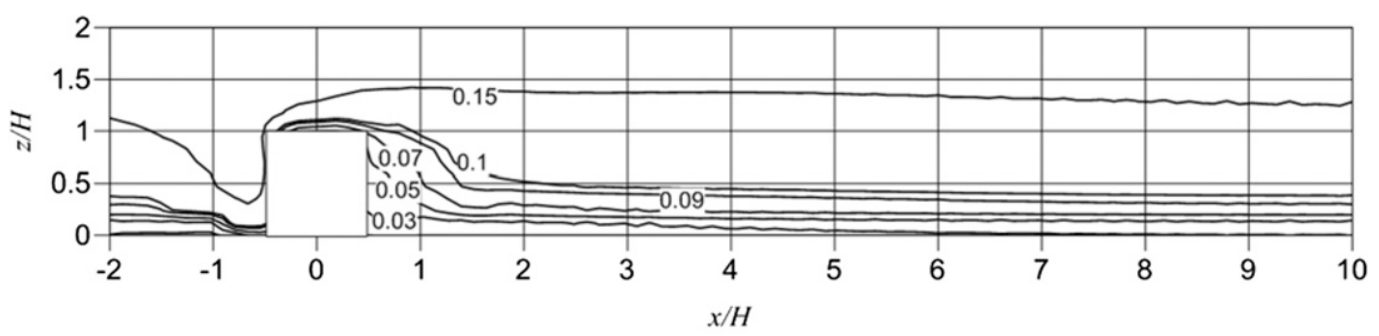

(a)neutral stratified condition

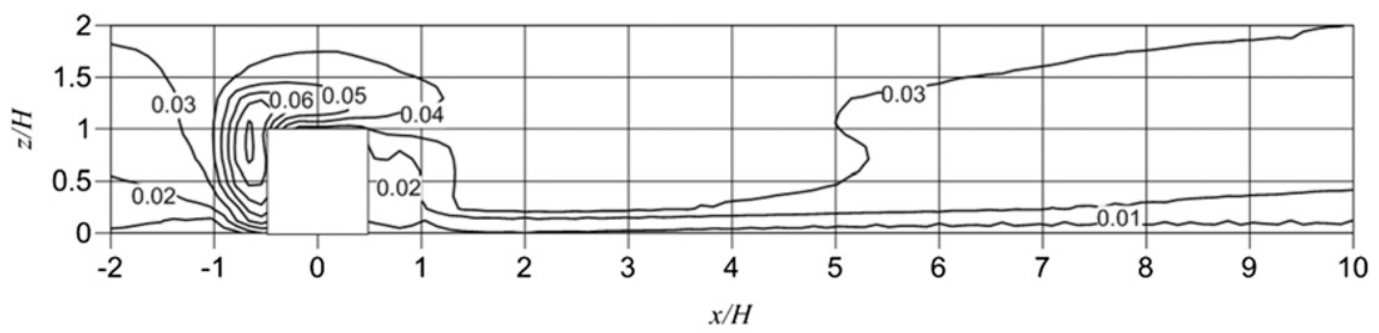

(b) stable stratified condition

FIG. 8. Vertical profiles of the turbulent kinetic energy on the central plane.

inflow. However, the recovery of the wind velocity is relatively slow under stable conditions.

When atmospheric stratification is stable, for $z / H<1.0$, the deficit in the velocity under stable conditions is slightly larger than that under neutral conditions, specifically at the points $x / H=1.5$ and 2.0. However, at $x / H=0.75$ and 1.0 , the effect of thermal stratification is not more prominent because of the mechanical disturbance produced by the building.

\section{b. Impact of the building on turbulence}

The profiles of turbulent kinetic energy under neutral and stable conditions in the numerical simulation are shown in Fig. 8. A comparison for the effect of the building on near-field turbulent kinetic energy at different positions is shown in Fig. 8.

Figure 8 shows that the values of turbulent kinetic energy are broadly great on the windward side of the building. This result is because the disturbance of the building results in a greater velocity gradient. The turbulent kinetic energy is large near the top of the building but small in the recirculation zone. However, the turbulent kinetic energy is still larger than that of the inflow state. The separated region of the building produces a larger turbulent kinetic energy, which continuously extends to a distance far downwind. When atmospheric stratification is stable, the variation in the turbulent kinetic energy is significantly smaller than that under neutral conditions, and the turbulent kinetic energy near the top of the building is smaller than that under neutral conditions. Kato and
Launder (1993) studied the effect of buildings on the structure of the flow field using various modified turbulence models. The results showed that these models better simulated the influence of a building on the structure of the flow field.

The effect of atmospheric stratification on turbulent kinetic energy is significant, and it influences the flow field and concentration distribution. Figure 9 shows the changes in the turbulent kinetic energy with increasing height at different positions under neutral and stable conditions. As shown in Fig. 9, when atmospheric stratification is stable, the variation in the turbulent kinetic energy levels at the different spots is significantly lower than that under neutral conditions. The probable reason could be that, when atmospheric stratification is stable, the vertical temperature gradient is larger than that under neutral conditions, thus suppressing atmospheric motion in the vertical direction. Hence, the variation in the turbulent kinetic energy is small.

The turbulence dissipation rate is the velocity at which the mechanical energy of an isotropic smallscale vortex transforms into thermal energy, which greatly influences the diffusion process. However, progress in the study of the turbulence dissipation rate is still limited due to its complexity. As shown in Fig. 10, with an increase in height, the turbulence dissipation rates vary at different positions under neutral and stable conditions.

From Fig. 10, the maximum turbulence dissipation rate is observed for $z / H<1.0$, and the maximum value 


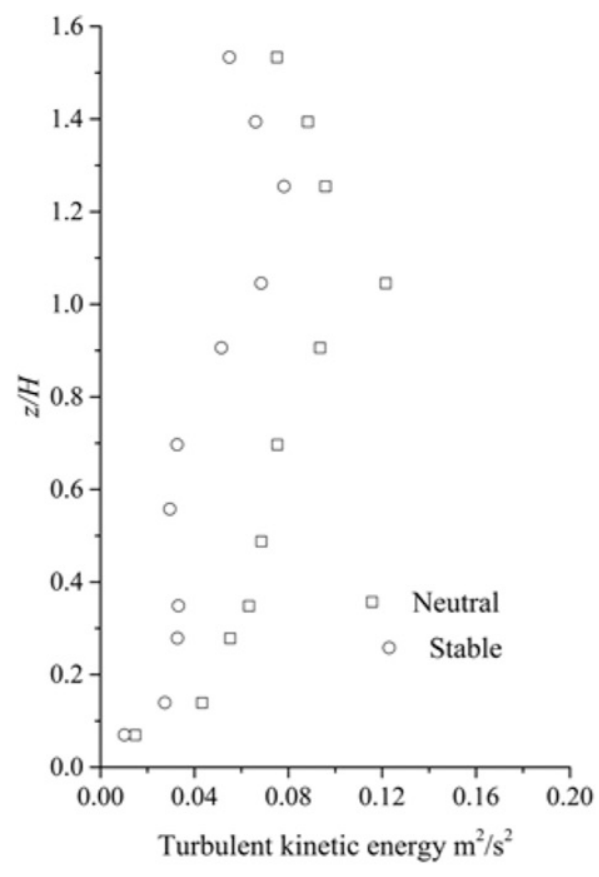

$$
x / H=0.75
$$

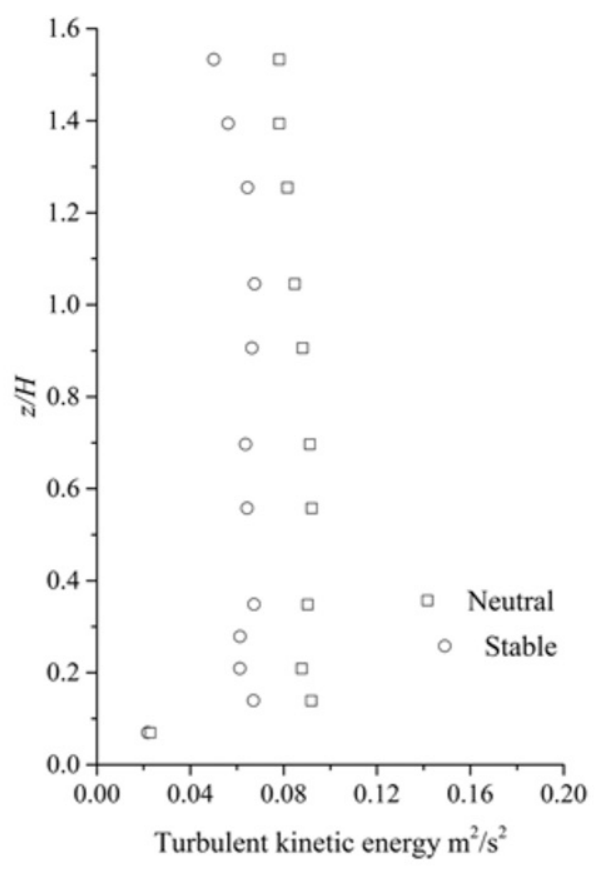

$$
x / H=1.5
$$

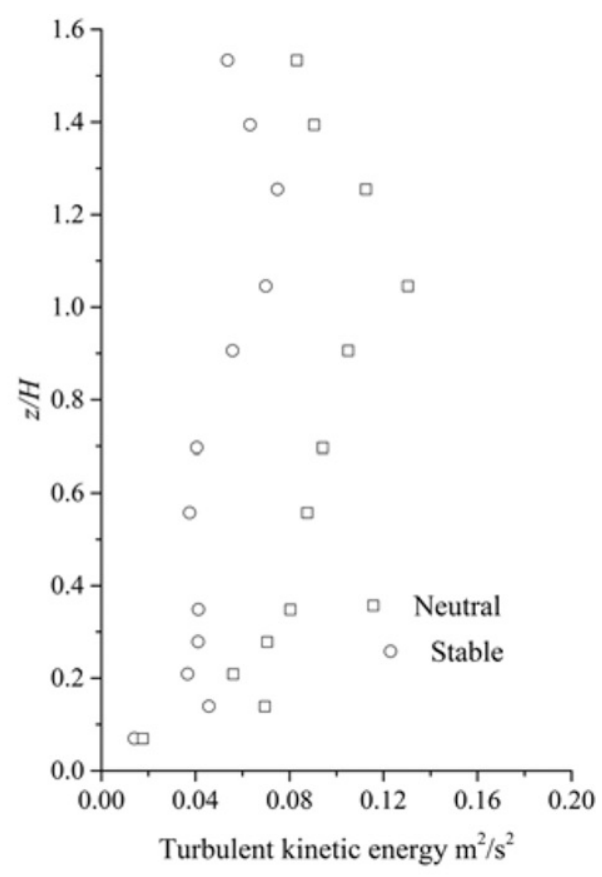

$$
x / H=1.0
$$

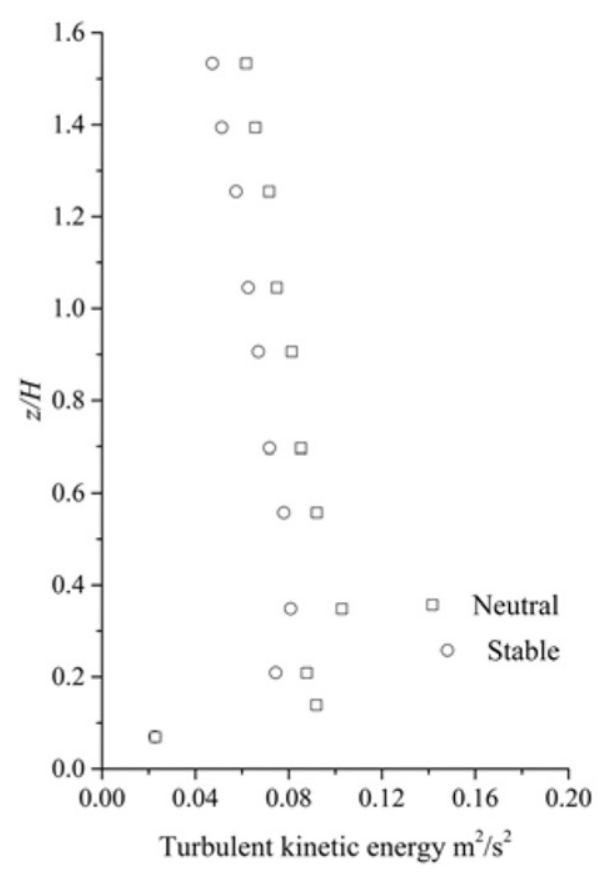

$x / H=2.0$

FIG. 9. The variation of turbulent kinetic energy as height $(z / H)$ increases.

appears at $x / H=0.75$ and 1.0 in the downwind direction. The main reason is that a larger wind shear appears near the recirculation zone because of the mechanical turbulence resulting from the building; hence, the maximum turbulence dissipation rate appears in the cavity zones. Thus, when atmospheric stratification is stable, the turbulence dissipation rate is slightly lower than that under neutral conditions. The influence of atmospheric stratification on the turbulence dissipation rate becomes gradually more 


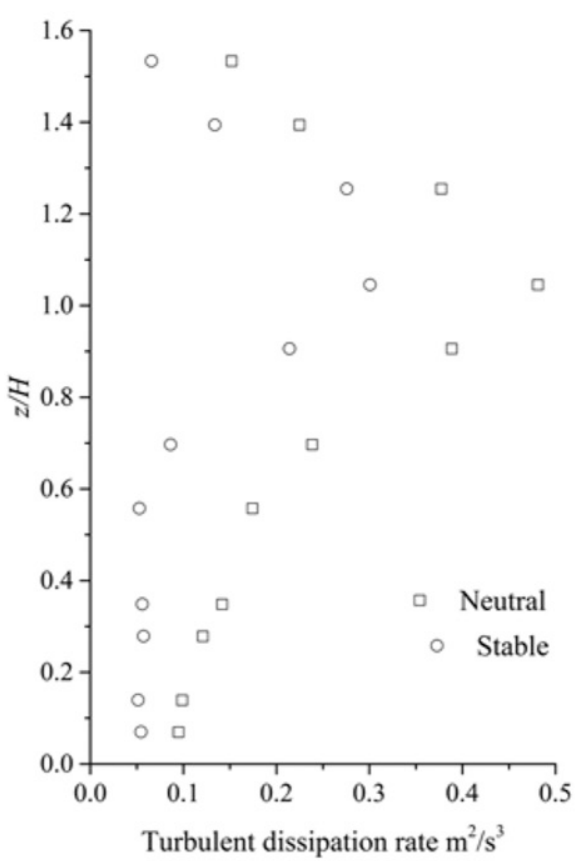

$x / H=0.75$

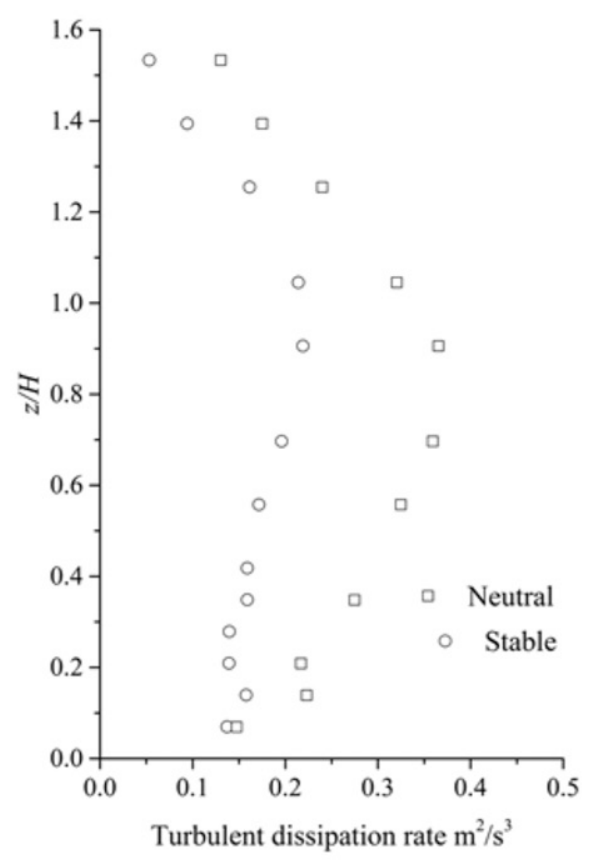

$x / H=1.5$

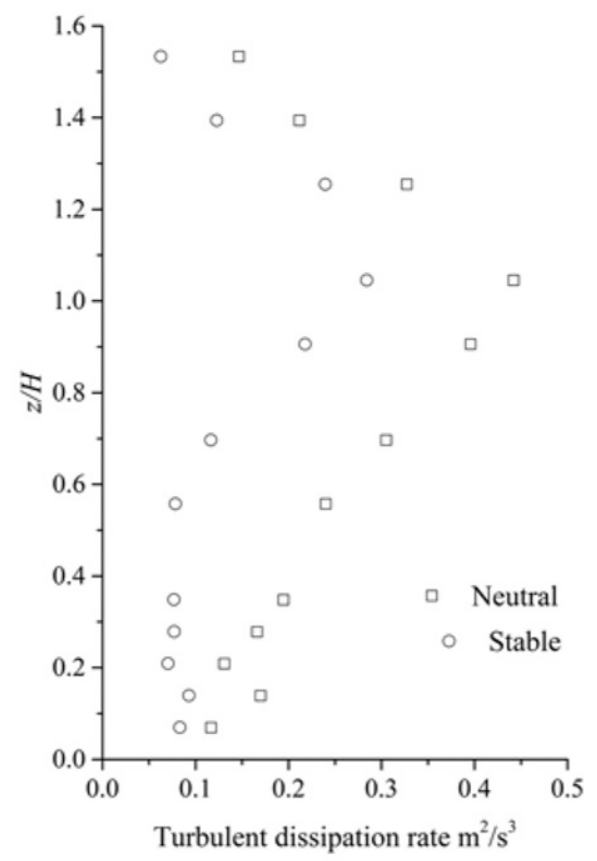

$x / H=1.0$

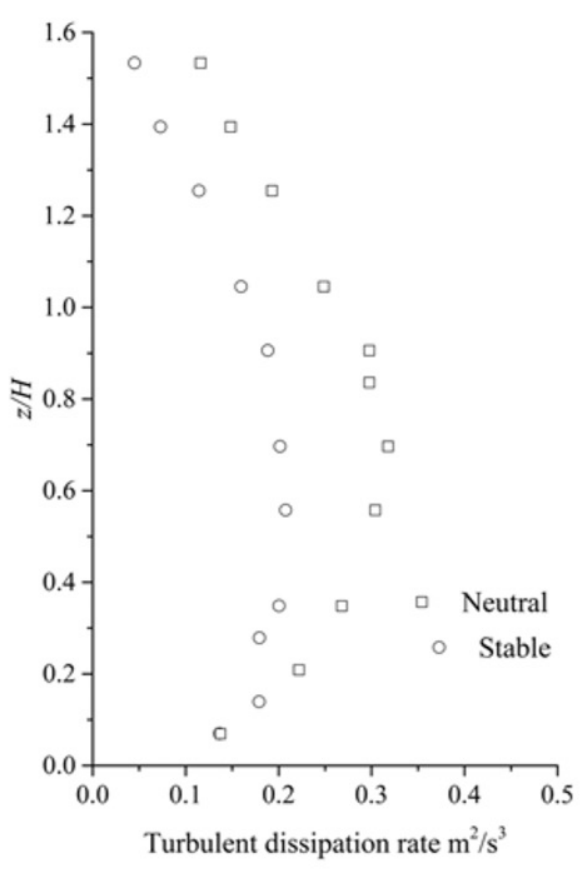

$x / H=2.0$

FIG. 10. The variation of the turbulence dissipation rate as height $(z / H)$ increases.

prominent with an increase in the distance (at $x / H=1.5$ and 2.0).

\section{c. The influence of the building on the concentration field}

To validate the simulated results for pollutant dispersion around a building using the $k-\varepsilon$ (RNG) turbulent model, a corresponding wind tunnel tracer experiment was conducted. The concentration distribution of pollutants is determined by the flow field and can reflect the changes in the flow field (Meroney and Cermak 1967). This experiment mainly considered the downwind concentration distribution under stable and neutral 


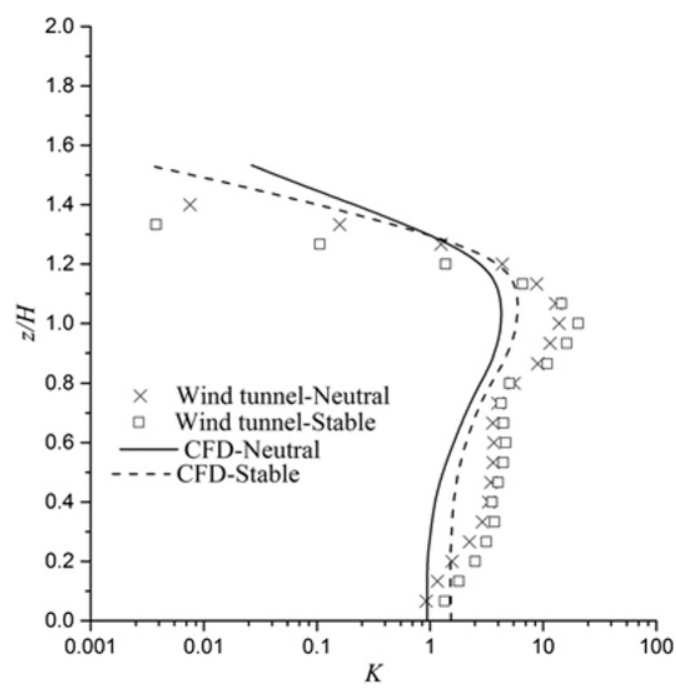

$x / H=0.75$

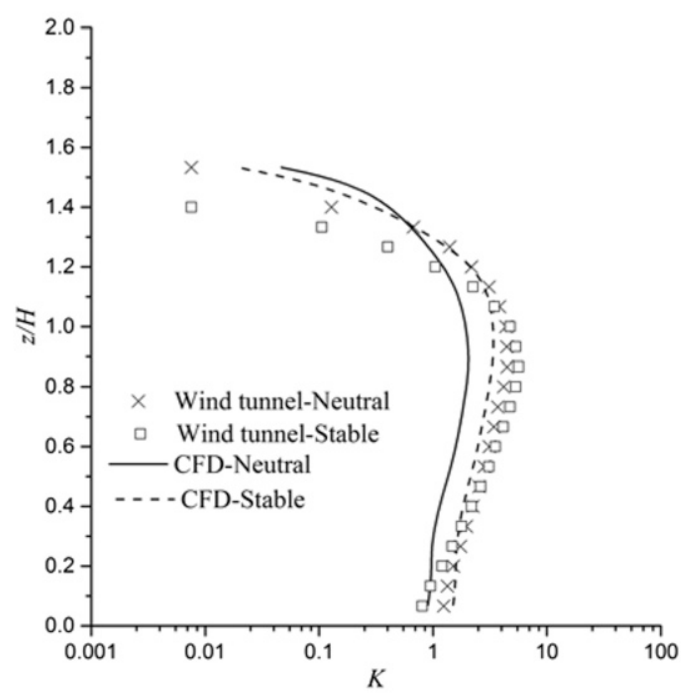

$x / H=1.5$

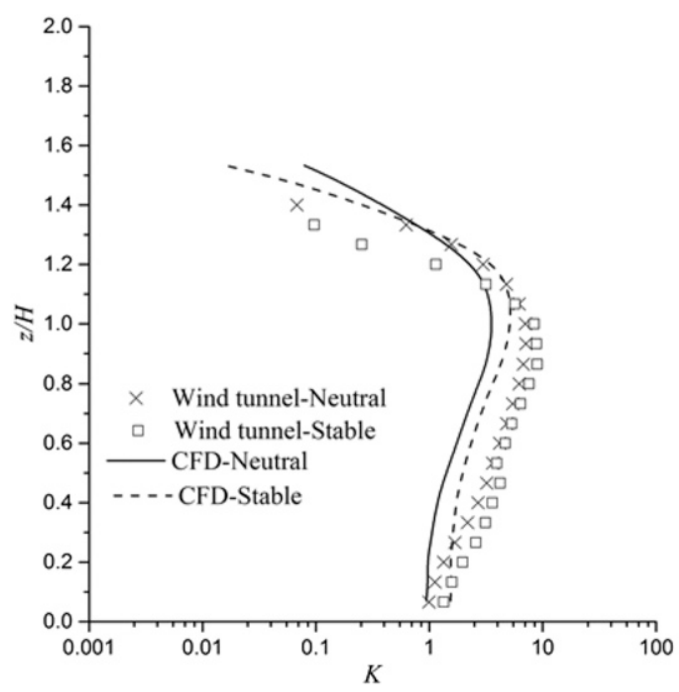

$x / H=1.0$

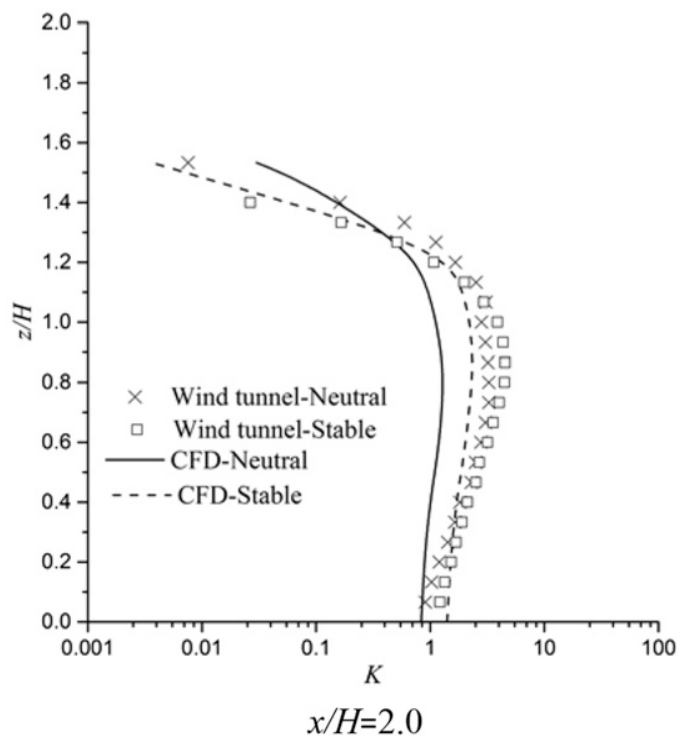

FIG. 11. Vertical profiles of mean concentration $K$.

conditions. Additionally, the near-ground horizontal distribution in the downwind direction and the vertical profiles along the central axis were measured. Moreover, the number of ground concentration samples was 300 , whereas the vertical concentration sampling number was 1000 . For a convenient comparison, the normalized concentration $K$ was used to calculate and compare the concentrations at different positions.

Figure 11 shows the comparison of the concentration results from the wind tunnel experiment and the numerical simulation under stable and neutral conditions. As shown in Fig. 11, the variations at different positions under neutral and stable conditions are similar in the numerical simulations and the wind tunnel experiments. The effect of atmospheric stability on pollutant dispersion is prominent; meanwhile, changes in concentration in the near wake region can be observed. The concentration results from the wind tunnel experiments are slightly greater than those from the numerical simulation for $z / H<1.2$. The reasons for this result could include the following. First, the turbulence model cannot accurately estimate the anisotropic turbulent stress and turbulent shear stress in the recirculation zone. Thus, the turbulence fluxes in both the horizontal and vertical directions are overestimated, and the estimation of the higher concentration gradient on the leeward side of the building is not completely accurate, resulting in a smoother concentration gradient (Santos et al. 2009). Second, the wind tunnel cannot adequately simulate the large-scale wind meander, which can be especially 
strong under stable conditions and can result in greater centerline concentrations in the wind tunnel (Mavroidis et al. 2003).

The patterns of concentration distribution are similar in the wind tunnel experiment and the numerical simulation. The concentrations gradually increase for $0.7<z / H<1.0$ but begin to decrease for $z / H>1.0$. Peak concentrations at different downwind positions are observed at $z / H=1.0$ under neutral and stable conditions. A downwash phenomenon appears near the building, mainly because the emission velocity from the stack is lower than the free stream velocity. The maximum concentration is observed at the downwind position of $x / H=0.75$, as the mechanical turbulence resulting from the building causes a larger turbulent intensity in the near region. In the wake region, the influence of atmospheric stratification on the concentration distributions becomes gradually apparent for $z / H>1.0$.

Yang and Meroney (1970) studied the behaviors of pollutant dispersion in the wake of a cube and found that stable stratification suppressed vertical spreading and caused the pollutant concentration to increase. The effect of thermal stability was weakened due to the mechanical turbulence caused by the building in the near region. Yassin (2013) studied the effect of thermal stratification on pollutant dispersion in the near wake of a building. The downwash phenomenon was observed under different thermal stratifications because the emission momentum from the stack was lower than the airflow velocity. Additionally, a maximum concentration was observed under stable conditions. In this paper, the results of the wind tunnel test and CFD simulation were in agreement with those of previous research.

Overall, the vertical spread of the plume under stable conditions is smaller than that under neutral conditions. The maximum concentrations are slightly higher than those under neutral conditions. The latter result is because the stability suppresses the vertical motion of airflow, where the near-ground pollutant concentration is higher than that under neutral conditions. These results show that the effect of atmospheric stability increases the pollutant concentrations in the wake region of the building under stable conditions.

Figure 12 compares the ground-level concentrations along the central axis $(y=0)$ under neutral and stable conditions in the wind tunnel experiments and the numerical simulation. As shown in Fig. 12, the concentrations for the stable condition are slightly greater than those for the neutral condition. This is because the height of plume raise under stable conditions is smaller than that under neutral conditions and the vertical distributions of the plume is suppressed by weak turbulence kinetic energy.

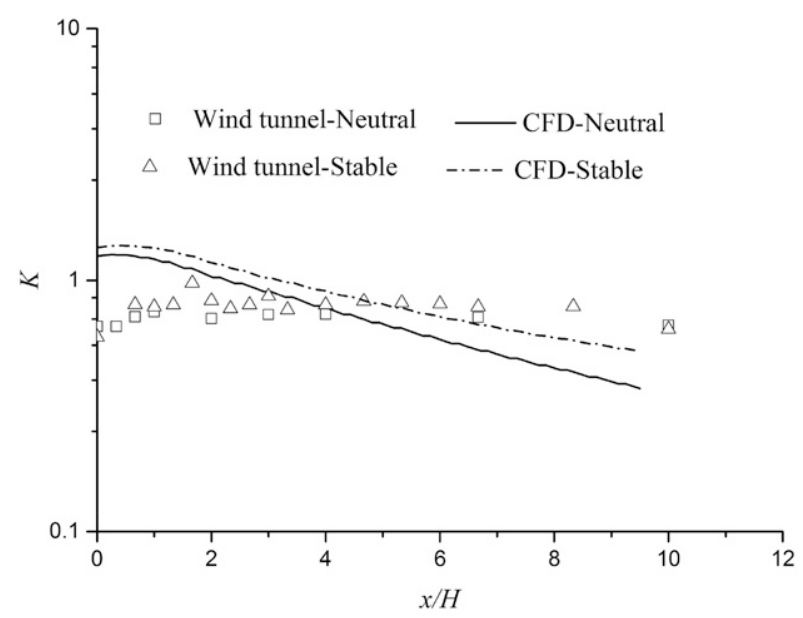

FIG. 12. Ground-level concentrations $K$ along the central ( $y$ ) axis.

In Fig. 12, at $x / H=3.0$, the concentrations in the numerical simulation are greater than those of the wind tunnel experiments under neutral and stable conditions. This is because CFD simulations overestimate the recirculation region and turbulence kinetic energy behind the building (Santos et al. 2009). Compared with the results of the wind tunnel experiment, simulated concentrations are slightly smaller for $x / H>6.0$ under stable conditions and for $x / H>4.0$ under neutral conditions. This is because large-scale wind meander is not reproduced in the wind tunnel, which can result in greater center-axis concentrations (Mavroidis et al. 2003). The maximum concentrations $K$ appear at $x / H=0.3$ in the numerical simulation $(K=1.2)$ and at $x / H=2.0$ in the wind tunnel experiment $(K=1.0)$ under stable conditions. The maximum concentrations appear at $x / H=0.2$ in the numerical simulation $(K=1.1)$ and at $x / H=1.0$ in the wind tunnel experiment $(K=0.9)$ under neutral conditions. Tominaga et al. (2008) conducted simulations to validate their wind tunnel experiments using standard and modified $k-\varepsilon$ models. The results showed that the concentration distribution calculated by the $k-\varepsilon$ (RNG) turbulent model was in better agreement with the data of the wind tunnel experiments than were those of other $k-\varepsilon$ models.

Figures 13 and 14 show the ground concentration contours for the neutral and stable conditions in the numerical simulations and wind tunnel experiments. As shown in Figs. 13 and 14, the patterns of concentration distribution in the numerical simulations are generally consistent with those in the wind tunnel experiments. The discrepancies between the results of the wind tunnel experiments and numerical simulation are caused by the different interpolation methods and deviations from the sampling points. 


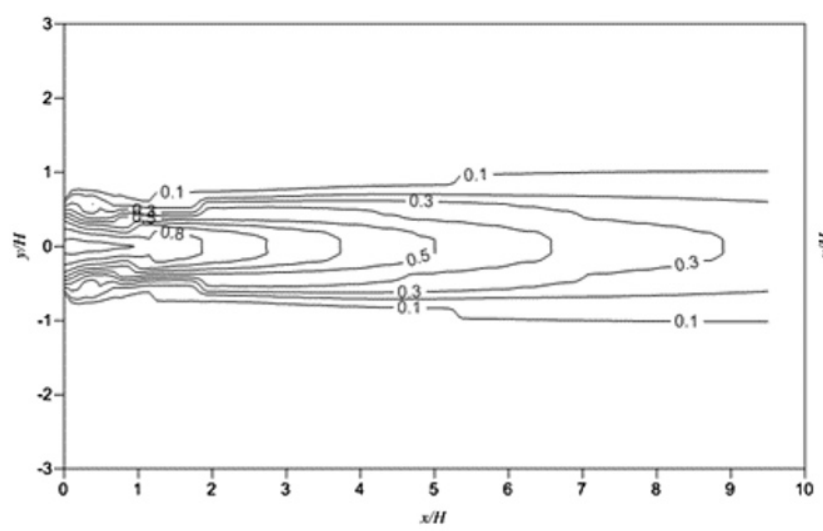

(a) neutral stratified condition

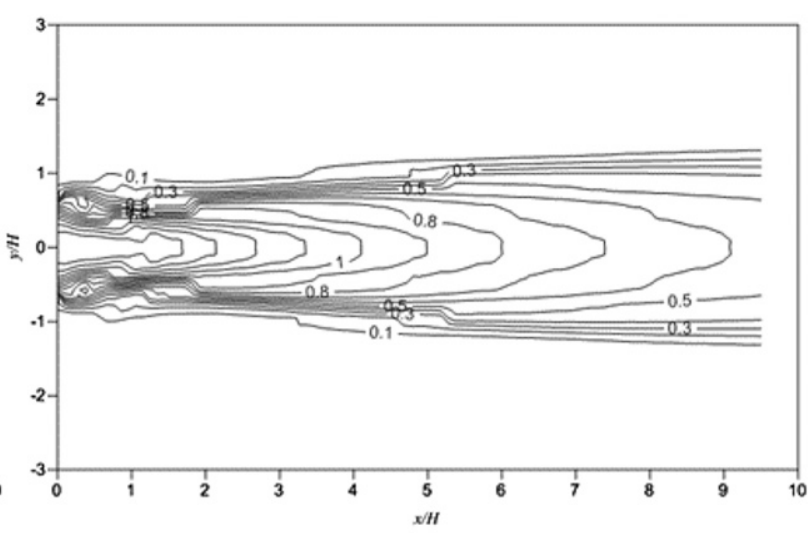

(b) stable stratified condition

FIG. 13. Contours of ground concentration $K$ in the downwind direction in the numerical simulation.

However, all the results reflect the dispersion characteristics of the pollutants around a building, where the maximum is observed in the wake region of the emission source. Compared to the wind tunnel experiments, the lateral spreading range of the plume is small under neutral and stable conditions in the numerical simulation. Additionally, Figs. 13 and 14 demonstrate that the lateral dispersion range under stable conditions is slightly larger than that under neutral conditions. The latter is mainly because stable stratification suppresses vertical airflow motion and reduces vertical spreading, which enhances lateral distribution.

\section{Conclusions}

Numerical simulation and wind tunnel experiments were conducted to study the effect of neutral and stable atmospheric stratifications on the diffusion of pollutants from a rooftop stack in the near wake region of a building. The main conclusions from the study are as follows:

1) When atmospheric stratification is stable, the nearground velocity in the wake region of the building was small, and the maximum deficit of velocity in the wake region of the building was larger than that under neutral conditions. The length of the recirculation region behind the building was longer than that under neutral conditions. The attachment point in the downwind direction of the building is observed at $x / H=2.0$ under neutral conditions and at $x / H=$ 3.0 under stable conditions.

2) The effect of thermal stability on the turbulent kinetic energy and turbulent dissipation rate became gradually more prominent with an increase in the downwind distance. The turbulent kinetic energy and turbulent dissipation rate were relatively large

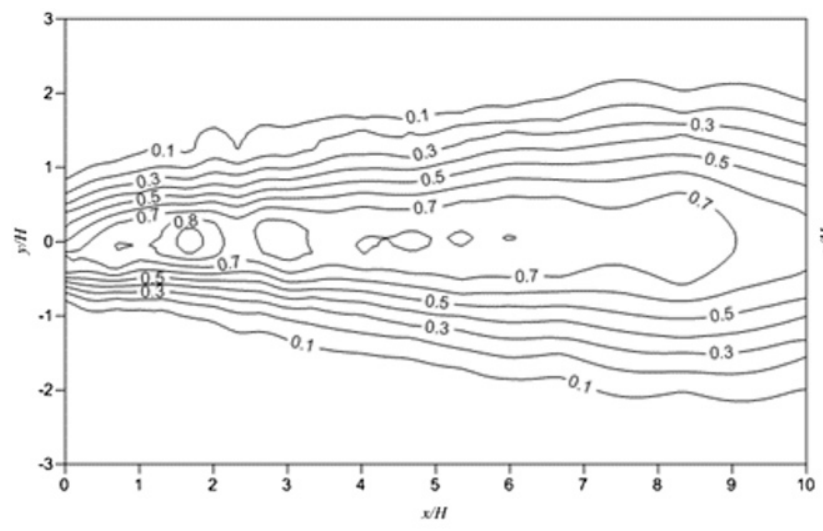

(a) neutral stratified condition

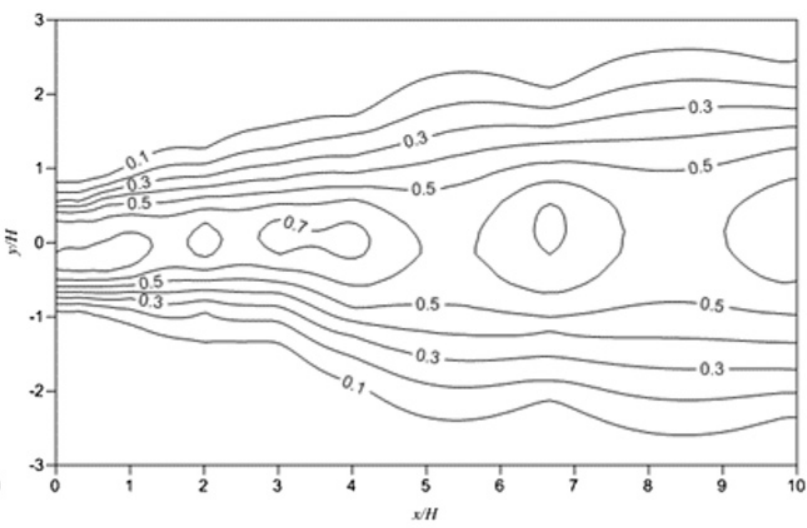

(b) stable stratified condition

FIG. 14. As in Fig. 13, but for the wind tunnel experiments. 
around the building because of the mutual influences of building disturbance and thermal stability.

3) A downwash phenomenon in the wake region of the building is observed through the vertical distribution of concentration. The maximum concentrations are observed at a height of $z / H=1.0$ under neutral and stable conditions. The concentrations increase in the wake region under stable conditions due to the effect of thermal stability. Meanwhile, the vertical distribution of the plume under stable conditions is observed to be smaller than that under neutral conditions.

In this paper, wind tunnel experiments and CFD numerical simulations were performed to study the patterns of flow and pollutant dispersion under neutral and stable atmospheric stratifications. Relevant measurement methods and simulation techniques for the stable atmospheric boundary layer were also introduced. An approach combining wind tunnel experiments and numerical simulation is efficient for investigating near-field pollutant dispersion when considering the mutual effects resulting from building and thermal stratification.

Acknowledgments. This work was supported by the Natural Science Fund of Shanxi Province (Grant 2015011055).

\section{APPENDIX}

\section{Description of the Symbols}

$n \quad$ Velocity index

$u \quad$ Wind velocity $\left(\mathrm{m} \mathrm{s}^{-1}\right)$

$U_{0} \quad$ Longitudinal mean velocity at the top of the modeling boundary layer $\left(\mathrm{m} \mathrm{s}^{-1}\right)$

$u_{*} \quad$ Surface friction velocity $\left(\mathrm{m} \mathrm{s}^{-1}\right)$

$y_{0} \quad$ Surface roughness length $(\mathrm{m})$

Re Reynolds number

$\mathrm{Ri}$ Richardson number

$C^{*} \quad$ Volume concentration at different downwind distances $\left(\mathrm{mg} \mathrm{m}^{-3}\right)$

$H \quad$ Height of the building (mm)

Hs Pollution source height $(\mathrm{mm})$

$Q \quad$ Source intensity $\left(\mathrm{m}^{3} \mathrm{~s}^{-1}\right)$

$\rho \quad$ Ambient air density $\left(\mathrm{kg} \mathrm{m}^{-3}\right)$

$k \quad$ Turbulent kinetic energy $\left(\mathrm{m}^{2} \mathrm{~s}^{-2}\right)$

$\varepsilon \quad$ Turbulence dissipation rate $\left(\mathrm{m}^{2} \mathrm{~s}^{-3}\right)$

$\mu_{t} \quad$ Turbulent viscosity $\left(\mathrm{m}^{2} \mathrm{~s}^{-1}\right)$

$g \quad$ Acceleration due to gravity $\left(\mathrm{m} \mathrm{s}^{-2}\right)$

$S_{i j} \quad$ Average strain rate tensor

$P_{T} \quad$ Turbulent stress

$P_{B} \quad$ Buoyancy stress

$K \quad$ Normalized concentration $\delta \quad$ Height of the boundary layer ( $\mathrm{mm}$ )

$T_{1} \quad$ Temperature of the ground $\left({ }^{\circ} \mathrm{C}\right)$

$T_{2} \quad$ Temperature of the top of the domain $\left({ }^{\circ} \mathrm{C}\right)$

$\mathrm{XL}$ Length of the computational domain (m)

YL Width of the computational domain (m)

ZL Height of the computational domain (m)

\section{REFERENCES}

Ai, Z. T., and C. M. Mak, 2017: CFD simulation of flow in a long street canyon under a perpendicular wind direction: Evaluation of three computational settings. J. Build. Environ., 114, 293-306, https://doi.org/10.1016/j.buildenv.2016.12.032.

Ashrafi, K., A. A. Orkomi, and M. S. Motlagh, 2017: Direct effect of atmospheric turbulence on plume rise in a neutral atmosphere. J. Atmos. Pollut. Res., 8, 640-651, https://doi.org/ 10.1016/j.apr.2017.01.001.

Berkowicz, R., and L. P. Prahm, 1982: Evaluation of the profile method for estimation of surface fluxes of momentum and heat. J. Atmos. Environ., 16, 2809-2819, https://doi.org/10.1016/ 0004-6981(82)90032-4.

Blocken, B., T. Stathopoulos, and J. Carmeliet, 2007: CFD simulation of the atmospheric boundary layer: Wall function problems. J. Atmos. Environ., 41, 238-252, https:// doi.org/10.1016/j.atmosenv.2006.08.019.

Endalew, A. M., M. Hertog, and M. A. Delele, 2009: CFD modeling and wind tunnel validation of airflow through plant canopies using 3D canopy architecture. J. Int. J. Heat Fluid Flow, 30, 356368, https://doi.org/10.1016/j.ijheatfluidflow.2008.12.007.

Flores, F., R. Garreaud, and R. C. Muñoz, 2013: CFD simulations of turbulent buoyant atmospheric flows over complex geometry: Solver development in OpenFOAM. J. Comput. Fluids, 82, 1-13, https://doi.org/10.1016/j.compfluid.2013.04.029.

Jiang, W. M., S. G. Miao, and H. N. Liu, 2003: Comparison and analysis of pollution modeling of a city sub-domain scale model with wind tunnel experiment. J. Acta Sci. Circumstantiae, 23, 652-656.

Kato, M., and B. E. Launder, 1993: The modeling of turbulent flow around stationary and vibrating square cylinders. Ninth Symp. on Turbulent Shear Flows, Kyoto, Japan, University of Kyoto, 10.4.1-10.4.6.

Mavroidis, I., R. F. Griffiths, C. D. Jones, and C. A. Biltoft, 1999: Experimental investigation of the residence of contaminants in the wake of an obstacle under different stability conditions. J. Atmos. Environ., 33, 939-949, https://doi.org/ 10.1016/S1352-2310(98)00219-2.

—_ — - and D. J. Hall, 2003: Field and wind tunnel investigations of plume dispersion around single surface obstacles. J. Atmos. Environ., 37, 2903-2918, https://doi.org/ 10.1016/S1352-2310(03)00300-5.

— , S. Andronopoulos, and J. G. Bartzis, 2012: Computational simulation of the residence of air pollutants in the wake of a 3 -dimensional cubical building. The effect of atmospheric stability. J. Atmos. Environ., 63, 189-202, https://doi.org/ 10.1016/j.atmosenv.2012.09.032.

Meroney, R. N., and J. E. Cermak, 1967: Wind tunnel modeling of flow and diffusion over San Nicolas Island. Pacific Missile Range Misc. Rep. PMR-MR-68-1, 124 pp., https://babel.hathitrust.org/cgi/ pt id $=$ uc1.31822033846858\&view $=1$ up\&seq $=7$.

_ B. M. Leitl, S. Rafailidis, and M. Schatzmann, 1999: Windtunnel and numerical modeling of flow and dispersion about 
several building shapes. J. Wind Eng. Ind. Aerodyn., 81, 333345, https://doi.org/10.1016/S0167-6105(99)00028-8.

Orkomi, A. A., K. Ashrafi, and M. S. Motlagh, 2018: New plume rise modeling in a turbulent atmosphere via hybrid RANSLES numerical simulation. J. Wind Eng. Ind. Aerodyn., 173, 132-146, https://doi.org/10.1016/j.jweia.2017.11.028.

Pieterse, J. E., and T. M. Harms, 2013: CFD investigation of the atmospheric boundary layer under different thermal stability conditions. J. Wind Eng. Ind. Aerodyn., 121, 82-97, https:// doi.org/10.1016/j.jweia.2013.07.014.

Santiago, J. L., R. Borge, and F. Martin, 2017: Evaluation of a CFDbased approach to estimate pollutant distribution within a real urban canopy by means of passive samplers. J. Sci. Total Environ., 576, 46-58, https://doi.org/10.1016/j.scitotenv.2016.09.234.

Santos, J. M., N. C. Reis Jr., E. V. Goulart, and I. Mavroidis, 2009: Numerical simulation of flow and dispersion around an isolated cubical building: The effect of the atmospheric stratification. J. Atmos. Environ., 43, 5484-5492, https://doi.org/ 10.1016/j.atmosenv.2009.07.020.

Tominaga, Y., and T. Stathopoulos, 2009: Numerical simulation of dispersion around an isolated cubic building: Comparison of various types of $k-\varepsilon$ models. J. Atmos. Environ., 43, 32003210, https://doi.org/10.1016/j.atmosenv.2009.03.038.

, and - , 2013: CFD simulation of near-field pollutant dispersion in the urban environment: A review of current modeling techniques. J. Atmos. Environ., 79, 716-730, https:// doi.org/10.1016/j.atmosenv.2013.07.028.

- A. Mochida, T. Shirasawa, R. Yoshie, H. Kataoka, K. Harimoto, and T. Nozu, 2004: Cross comparisons of CFD results of wind environment at pedestrian level around a high-rise building and within a building complex. J. Asian Archit. Build. Eng., 3, 63-70, https://doi.org/10.3130/jaabe.3.63.
- - - and S. Murakami, 2008: Comparison of various revised $k-\varepsilon$ models and LES applied to flow around a high-rise building model with 1:1:2 shape placed within the surface boundary layer. J. Wind Eng. Ind. Aerodyn., 96, 389-411, https://doi.org/10.1016/j.jweia.2008.01.004.

Uehara, K., S. Murakami, S. Oikawa, and S. Wakamatsu, 2000: Wind tunnel experiments on how thermal stratification affects flow in and above urban street canyons. J. Atmos. Environ., 34, 1553-1562, https://doi.org/10.1016/S1352-2310(99) 00410-0.

Yang, B. T., and R. N. Meroney, 1970: Gaseous dispersion into stratified building wakes. Colorado State University Rep. CER70-71 BTY-RNM-8.R, 114 pp., https://www.researchgate.net/ publication/253926014_Gaseous_dispersion_into_stratified_ building_wakes.

Yao, R. T., Q. D. Qiao, H. Hao, and X. Yu, 2002: Wind tunnel simulation of flow and dispersion around complex buildings. J. Radiat. Prot. Bull., 6, 1-6.

Yassin, M. F., 2013: A wind tunnel study on the effect of thermal stability on flow and dispersion of rooftop stack emissions in the near wake of a building. J. Atmos. Environ., 65, 89-100, https://doi.org/10.1016/j.atmosenv.2012.10.013.

—, S. Kato, R. Ooka, T. Takahashi, and R. Kouno, 2005: Field and wind-tunnel study of pollutant dispersion in a builtup area under various meteorological conditions. $J$. Wind Eng. Ind. Aerodyn., 93, 361-382, https://doi.org/10.1016/ j.jweia.2005.02.005.

Zhang, Y. Q., S. P. Arya, and W. H. Snyder, 1996: A comparison of numerical and physical modeling of stable atmospheric flow and dispersion around a cubical building. J. Atmos. Environ., 30, 1327-1345, https://doi.org/10.1016/ 1352-2310(95)00326-6. 